\title{
Anticoagulation in critically ill patients on mechanical ventilation suffering from COVID-19 disease, The ANTI-CO trial: A structured summary of a study protocol for a randomised controlled trial
}

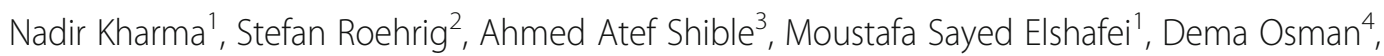
Ingi Mohamed Elsaid ${ }^{4}$, Salma Faisal Mustafa ${ }^{4}$, Asjad Aldabi ${ }^{4}$, Osamah A.M. Smain ${ }^{4}$ and Marcus D. Lance $2^{2^{*}}$ (D)

\begin{abstract}
Objectives: To assess the effect of anticoagulation with bivalirudin administered intravenously on gas-exchange in patients with COVID-19 and respiratory failure using invasive mechanical ventilation.

Trial design: This is a single centre parallel group, superiority, randomized (1:1 allocation ratio) controlled trial.

Participants: All patients admitted to the Hamad Medical Corporation -ICU in Qatar for COVID-19 associated respiratory distress and in need of mechanical ventilation are screened for eligibility.

Inclusion criteria: all adult patients admitted to the ICU who test positive for COVID-19 by PCR-test and in need for mechanical ventilation are eligible for inclusion. Upon crossing the limit of D-dimers $(1.2 \mathrm{mg} / \mathrm{L})$ these patients are routinely treated with an increased dose of anticoagulant according to our local protocol. This will be the start of randomization.

Exclusion criteria: pregnancy, allergic to the drug, inherited coagulation abnormalities, no informed consent.

Intervention and comparator: The intervention group will receive the anticoagulant bivalirudin intravenously with a target aPTT of 45-70 sec for three days while the control group will stay on the standard treatment with lowmolecular-weight heparins /unfractionated heparin subcutaneously (see scheme in Additional file 1). All other treatment will be unchanged and left to the attending physicians.

Main outcomes: As a surrogate parameter for clinical improvement and primary outcome we will use the $\mathrm{PaO} 2 /$ $\mathrm{FiO} 2$ (P/F) ratio.

Randomisation: After inclusion, the patients will be randomized using a closed envelope method into the conventional treatment group, which uses the standard strategy and the experimental group which receives anticoagulation treatment with bivalirudin using an allocation ratio of 1:1.

(Continued on next page)
\end{abstract}

\footnotetext{
* Correspondence: Mlance@hamad.qa

${ }^{2}$ Department of Anesthesiology, Intensive Care and Perioperative Medicine, Hamad Medical Corporation (HMC), Al-Rayyan Road, Doha, Qatar

Full list of author information is available at the end of the article
}

C C The Author(s). 2020 Open Access This article is licensed under a Creative Commons Attribution 4.0 International License, which permits use, sharing, adaptation, distribution and reproduction in any medium or format, as long as you give appropriate credit to the original author(s) and the source, provide a link to the Creative Commons licence, and indicate if changes were made. The images or other third party material in this article are included in the article's Creative Commons licence, unless indicated otherwise in a credit line to the material. If material is not included in the article's Creative Commons licence and your intended use is not permitted by statutory regulation or exceeds the permitted use, you will need to obtain permission directly from the copyright holder. To view a copy of this licence, visit http://creativecommons.org/licenses/by/4.0/. The Creative Commons Public Domain Dedication waiver (http://creativecommons.org/publicdomain/zero/1.0/) applies to the data made available in this article, unless otherwise stated in a credit line to the data. 
(Continued from previous page)

Blinding (masking): Due to logistical and safety reasons (assessment of aPTT to titrate the study drug) only the data-analyst will be blinded to the groups.

Numbers to be randomised (sample size): We performed a sample size calculation and assumed the data for P/F ratio (according to literature) is normally distributed and used the mean which would be: 160 and SD is 80 . We expect the treatment will improve this by 30\%. In order to reach a power of $80 \%$ we would need 44 patients per group (in total 88 patients). Taking approximately 10\% of dropout into account we will include 100 patients (50 in each group).

Trial Status: The local registration number is MRC-05-082 with the protocol version number 2. The date of approval is 18th June 2020. Recruitment started on 28 th June and is expected to end in November 2020.

Trial registration: The protocol is registered before starting subject recruitment under the title: "Anticoagulation in patients suffering from COVID-19 disease. The ANTI-CO Trial" in ClinicalTrials.org with the registration number: NCT04445935. Registered on 24 June 2020.

Full protocol: The full protocol is attached as an additional file, accessible from the Trials website (Additional file 2). In the interest in expediting dissemination of this material, the familiar formatting has been eliminated; this Letter serves as a summary of the key elements of the full protocol.

Keywords: COVID-19, randomised controlled trial, protocol, anticoagulation, thrombosis, Anti-Co trial

\section{Supplementary information}

Supplementary information accompanies this paper at https://doi.org/10. 1186/s13063-020-04689-1.

\section{Additional file 1.}

Additional file 2. Full Study Protocol.

\section{Acknowledgements}

We acknowledge all members of the care team and all participants and their families.

\section{Authors' contributions}

NK, ML: design, preparing the protocol and the manuscript and execution of the study. SR, AS, ME, DO, IE, SM, AA, OS: design, execution of the study and preparation of the manuscript. The author(s) read and approved the final manuscript.

\section{Funding}

This project was supported by HMC only. HMC plays no part in study design; collection, management, analysis, and interpretation of data; writing this summary; and decisions to submit a report for publication.

\section{Availability of data and materials}

The final dataset will be available to the research-team, to the local authorities and upon reasonable request to others after agreement of the local IRB. All data are anonymised and stored safely for five years according to local law.

\section{Ethics approval and consent to participate}

This trial has been approved on $18^{\text {th }}$ June 2020 by HMC-IRB under the trial number MRC-05-082.

I declare this IRB acts fully independent as an ethical committee and adheres to local law, GCP and the Helsinki Declaration.

All participants are consented personally. If the participant is not able to give consent them self their legal representative is eligible to consent. If this person is not available a deferred consent is taken, which needs later confirmation by the participant or their legal representative.

\section{Consent for publication}

Not applicable

\section{Competing interests}

The authors declare that they have no competing interests.

\section{Author details}

${ }^{1}$ Department of Medical Intensive Care, Hamad Medical Corporation (HMC), Al-Rayyan Road, Doha, Qatar. 'Department of Anesthesiology, Intensive Care and Perioperative Medicine, Hamad Medical Corporation (HMC), Al-Rayyan Road, Doha, Qatar. ${ }^{3}$ Department of Pharmacy, Hamad Medical Corporation (HMC), Al-Rayyan Road, Doha, Qatar. ${ }^{4}$ Department of Medical Education, Hamad Medical Corporation (HMC), Al-Rayyan Road, Doha, Qatar.

Received: 12 August 2020 Accepted: 14 August 2020

Published online: 07 September 2020

\section{Publisher's Note}

Springer Nature remains neutral with regard to jurisdictional claims in published maps and institutional affiliations. 